\title{
ENHANCEMENT OF THE PROCESSES OF DESICCANT AIR CONDITIONING SYSTEM
}

\author{
A. E. Kabeel ${ }^{1}$, Ali M Almagar ${ }^{2}$ \\ ${ }^{1}$ Faculty of Engineering, Tanta University, Tanta, Egypt, Fax0020403453960, kabeel6@hotmail.com \\ ${ }^{2}$ Environmental Energy Engineering Consultants, KSA, Fax 00096622834301,al-magar@hotmail.com
}

\begin{abstract}
An experimental study was carried out to evaluate the liquid desiccant system performance during dehumidification and humidification processes using air injection through the liquid desiccant solution (Calcium Chloride). The air flows cross the desiccant solution with different air mass flow rates. The system is studied at different operating condition (air flow rate, temperature, humidity ratio and solution levels). The effectiveness of the proposed system for both dehumidification and humidification processes were evaluated. Also, the cooling effect and mass transfer coefficient was obtained. It is found that the system effectiveness reached 0.75 in the dehumidification process and 0.7 in the humidification process. Mass transfer coefficient depends on the air mass flow rate and the desiccant solution level in the tank Economical Results of the presented system is estimated
\end{abstract}

Keywords : Air humidification, Air dehumdificaion, Liquid Desiccant

\section{INTRODUCTION}

In traditional cooling systems, dehumidification is achieved by cooling a moist air stream to a temperature below its dew point so that liquid water condenses out of the air. This process is familiar to anyone who has seen moisture condense on a glass of ice water on a humid day. The process is illustrated from point 1 to 2 on a psychometric chart in Fig1. From points 1 to 2, the air passes through the cooling coil, the dry bulb temperature continues to decrease as moisture begins to condense out of the air onto the cooling coil, resulting in a simultaneous decrease in the moisture content of the air. Air leaving the cooling coil typically is too cold to deliver directly to the space. In order to deliver air at the desired condition, some form of reheating must be used. The reheat process path is shown in Figure 1, Because a standard cooling system is controlled by a thermostat, the system will only run long enough to satisfy the temperature requirement of the thermostat. Also, the moisture standing on the coils when the unit shuts off can re-evaporate in to the air, another disadvantage of using the cooling coil approach is that the air leaving the coil is nearly saturated, with a relative humidity typically above $90 \%$. This moist air travels through duct work until it either is mixed with dryer air or reaches the reheat unit.

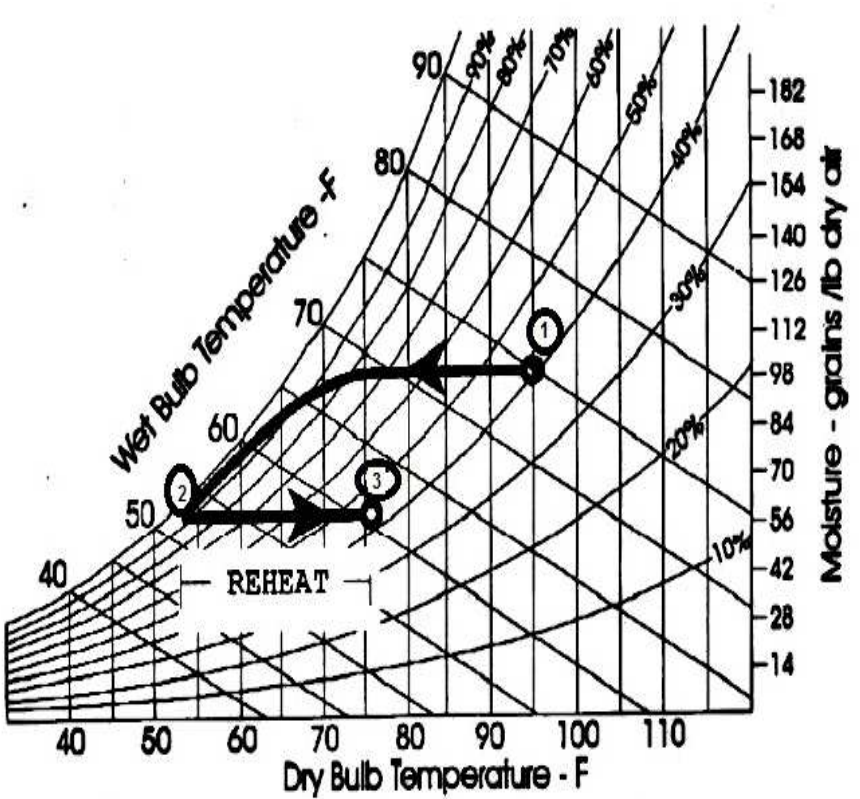

Figure 1: Cooling Coil Dehumidification Process

The damp ducts, along with wet evaporator coils and standing water in a condensate collection pan, can facilitate problems with microbial growth and pose associated health, odor. The approximate path of the process air through a desiccant device is depicted in Figure 2 for the same inlet and outlet conditions as were shown for the sub-cooling system (Figure 1). 


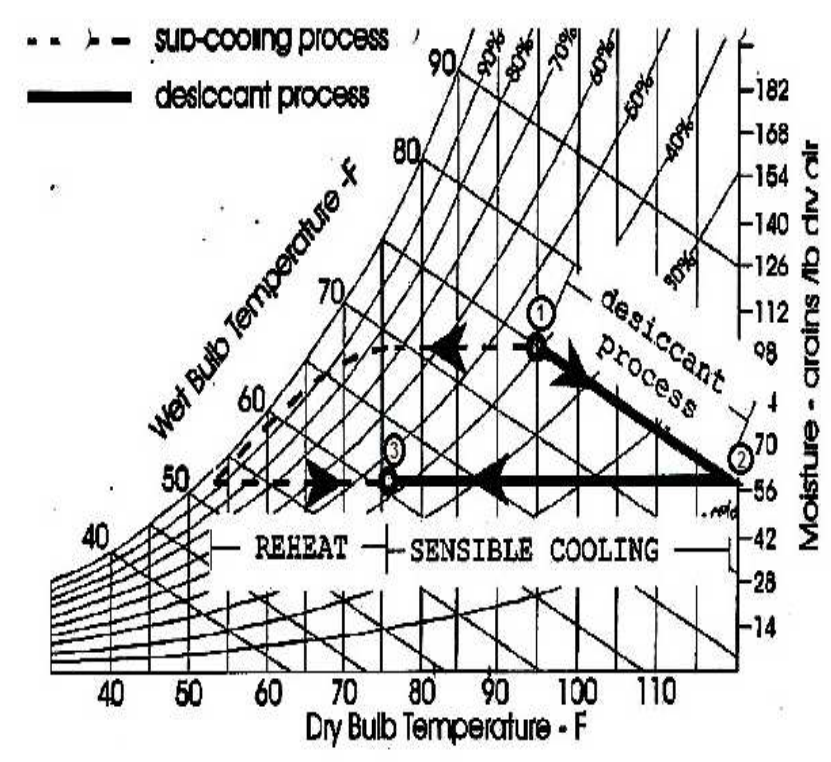

Figure 2: Desiccant Dehumidification Process

As implied by the path from points 1 to 2 in Figure 2, the desiccant process increases the dry bulb temperature of the process air. The path from point 1 to 2 is close to a line of constant enthalpy. After the dehumidification process, the process air must undergo a sensible cooling procedure to reach the desired end point, points 2 to 3 . This is also illustrated in Figure.2.

Dehumidification is one the most important components in liquid desiccant air conditioning system. Desiccant dehumidification has long been adopted for both industrial and agricultural purposes, such as humidity control in textile mill and post harvest low- temperature crop-drying in stores, and is now taking a more and more prominent role in the air conditioning field. Its economical and effective humidity control at low and moderate temperature really dwarfs the conventional method of humidity control, which is generally by lowering the air temperature to around the dry bulb temperature

Dehumidifying air by direct contact with desiccant-air systems can be used in drying crops. Removal of moisture from air before passing over the dried products decreases the need for high inlet temperatures of air. In the dehumidification process, the air is passed over a thin layer of strong liquid desiccant. The desiccant absorbs the moisture from the air passing over it. The desiccant is diluted during this process. This liquid can be regenerated to the required concentration by using solar energy.

Several materials can be employed as the desiccant both solid and liquid. Liquid desiccant dehumidification has been proved to be an effective method to extract the moisture of air with relatively less energy consumption compared with conventional vapor compression system. Calcium chloride is the cheapest and most readily available desiccant, but its vapor pressure at a given temperature is relatively high, and its unstable conditions depending on inlet air conditions and desiccant concentration in solution limit its widespread use.

Several works were done to investigate the performance of liquid desiccant system [1], [2], [3] and [4] .The physical properties of a proposed liquid desiccant such as density, viscosity, and vapor pressure were obtained [5]

There are three basic configurations of a liquid desiccant dehumidifier vessel. It can be a spray chamber, a packed tower, or a sprayed coil arrangement. In a spray chamber, the liquid desiccant is atomized into the air stream using high pressure nozzles. In a packed tower, a liquid film flows downward over the surface of the packing while air is passed in the opposite direction through the packing. The dry air exiting the spray chamber or the packed tower is then cooled by a sensible heat exchanger to remove the heat of sorption. In contrast, a sprayed coil dehumidifier combines dehumidification and sensible cooling in a single piece of equipment. The liquid desiccant is sprayed over finned coils that carry water supplied by a cooling tower or other means. The regeneration process can also utilize a spray chamber, a packed tower, or a sprayed coil arrangement analogous to the corresponding components in the dehumidifier. In all cases, heat must e provided for regeneration. In addition, regeneration can be accomplished by exposing a falling-liquid solution film to solar radiation and ambient. A transparent cover may be placed over he liquid film to form a rectangular channel for airflow. This increases the liquid temperature, but he air humidity in the channel is higher than that of ambient air. the selection of a suitable liquid desiccant is of paramount importance. The following guidelines should be considered when choosing liquid desiccants: They should have suitable water vapor pressures for absorption and desorption throughout the expected range of operating conditions of the process air stream [6]

The dehumidification and humidification process of desiccant solution by air injection through the liquid desiccant solution ( calcium chloride), the system effectiveness reached to 0.87 in dehumidification and about 0.92 in the humidification process Studied [7]. Also, the mass transfer coefficient reached $28 \mathrm{~kg} \mathrm{~s}^{-1}$ $\mathrm{m}^{2} \mathrm{~mm} \mathrm{Hg}$ at an air mass flow rate of $0.022 \mathrm{~kg} \mathrm{~s}^{-1}$ in the dehumidification process.

The performance analysis of a no-frost hybrid air conditioning system with integrated liquid desiccant dehumidification studied [8]. In this system, the sensible heat load is primarily treated by a vapor compression heat hump; the latent heat load is treated by a liquid dehumidification system that uses a lithium chloride 
solution as a desiccant. They found that, Compared to a traditional air conditioning system, the hybrid air conditioning system improves the coefficient of performance (COP) by approximately $20 \%$ and $100 \%$ in summer and winter, respectively.

The performance analysis of liquid desiccant dehumidification systems studied [9]. It is found that, the analysis of different empirical dehumidification effectiveness correlations for packed bed columns using three desiccant solutions viz. triethylene glycol, lithium chloride and calcium chloride has been reported in this paper. The analysis shows wide variations in effectiveness values ranging from $10 \%$ to $50 \%$ or more, with higher deviations occurring for lower ratios of liquid to gas flow rates.

The performance of absorption and regeneration columns for a liquid desiccant-vapor compression hybrid system for the solution to air (S/A) flow ratio are very low in the range of $0.05-3 \%$. The liquid desiccant is used only for dehumidification of supply air in the absorber which can be subsequently regenerated in the regenerator using condenser heat studied [10]. The analysis shows that higher the specific humidity and lower the temperature of the inlet air, higher will be the dehumidification in the absorber. Similarly, the regeneration can be increased by increasing the temperature and decreasing the specific humidity of the inlet air to the regenerator. Further, the solution temperature has negligible effect on the performance of air dehumidification or solution regeneration owing to low flow rate of the solution.

The performance analysis of liquid desiccant cooling systems for air conditioning in residential buildings studied [11[. The best dehumidification performance at no temperature increase was obtained in an evaporative cooled heat exchanger with sprayed lithium chloride solution. $U p$ to $7 \mathrm{~g} / \mathrm{kg}$ dehumidification could be reached in an isothermal process, although the surface wetting of the first prototype was low. The process then provides inlet air conditions below $208 \mathrm{C}$ for the summer design conditions of $32{ }^{\circ} \mathrm{C}, 40 \%$ relative humidity. With air volume flow rates of $200 \mathrm{~m}_{3} / \mathrm{h}$ the system can provide $886 \mathrm{~W}$ of cooling power.

The hybrid liquid desiccant based air-conditioning system. A hybrid open-cycle vapor absorption and liquid desiccant system using $\mathrm{LiBr}$ for the process of absorption and dehumidification studied [12]. The hybrid model presented is found to be an excellent alternative to conventional vapor absorption machines, particularly in hot and humid climates. The COP so obtained is about $50 \%$ higher than that of a conventional vapor absorption machine.
Once the liquid desiccant has absorbed the moisture it has to be regenerated. Different methods are reported in literature. Lowenstein and Dean [13] have investigated advanced separation processes for liquid desiccant in HVAC applications. These options have otherwise been used widely in the chemical processes industries. However the initial cost of equipment of advanced separation process is high. Peng and Howell [14] have discussed the performance of various types of regenerators for liquid desiccants in air-conditioning applications using solar energy. It was concluded that the finned tube heat exchanger with spray nozzles is the most practical equipment for regeneration. However, the initial cost and electric power consumption are high. .Investigations and experiments found that calcium chloride is the cheapest and most readily available desiccant, but its vapour pressure at a given temperature is relatively high, and its unstable conditions depending on inlet air conditions and desiccant concentration in solution limit its widespread use.

There are generally three flow patterns for the dehumidifier, namely parallel flow, counter flow, and cross flow. Rahamah et al. [15] gave the theoretical analysis for parallel flow liquiddesiccant dehumidification based on control volume approach. Their analysis shows that low air flow rate and increased channel height produce better dehumidification and cooling processes. Low air flow rate will increase the contacting time between air and desiccant thus improves mass transfer; however, a certain minimum flow rate of the liquid is needed for the normal function dehumidifier. Increasing channel height will enlarge the contacting area between air and desiccant, which also enhances mass transfer. Rahamah et al. [16] analyzed the parallel flow channel between air and solution film in a fin-tube arrangement.

Liquid-desiccant dehumidification techniques have made great strides in the past decades, and some are commercialized and employed to satisfy industrial and residential needs. Theoretical models about desiccant dehumidification have been established and insightful analysis has been performed. However, it is still uncertain about the exact process of mass and heat transfer, such as the absorption heat distribution between desiccant solution film and process air, wetting ratio of the desiccant solution. An idea that improves the absorption and regeneration process studied in the present work. The dehumidification and humidification process studied with the air injection through the liquid solution (Calcium chloride). Calcium chloride solution is a cheap desiccant. The experiments were carried at different inlet conditions (Temperature, air flow rate and humidity ratio). In addition, the study presents the effect of the operating conditions on the performance of the proposed system during dehumidification and humidification processes at different levels of solution in the tank 


\section{EXPERIMENTAL SET-UP}

An experimental set up was developed to carry out studies on air injection through the liquid desiccant (Calcium chloride) during dehumidification and humidification processes (Fig. 3), Solution tank with dimensions $40 \times 40 \times 50 \mathrm{~cm}$ contains the desiccant solution. It is made from galvanized iron sheet $2 \mathrm{~mm}$ thick.

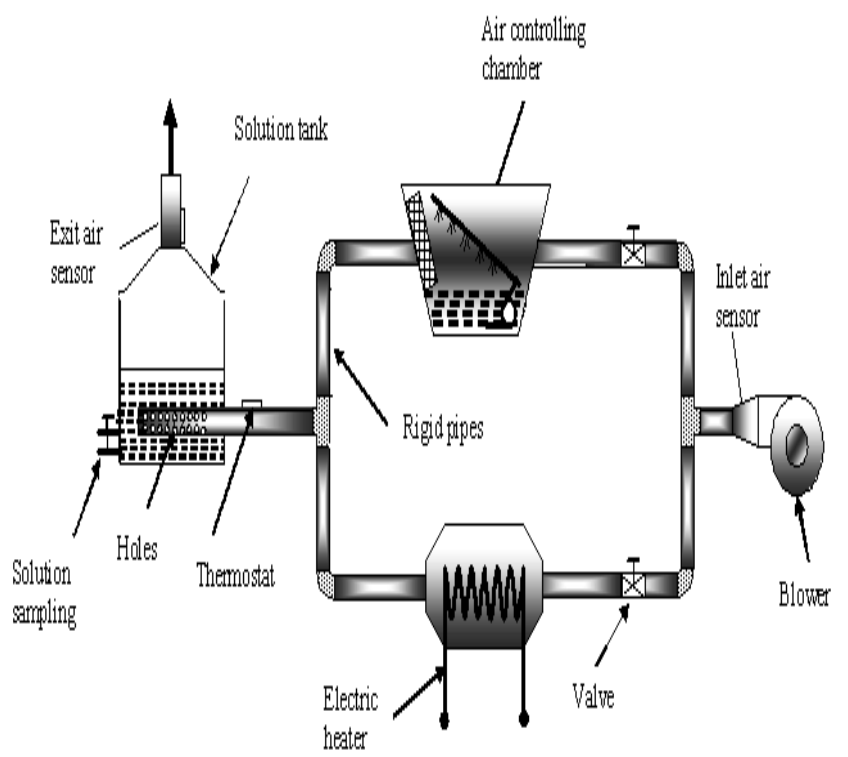

Fig. (3) Experimental setup of the proposed system.

Blower is used to inject the external air through the solution tank with different air mass flow rates. Outside air from the fan can pass in two paths where one can be used during experimental work. In the experiment, an air washer is located before the solution tank to control moisture of incoming air, which flow through the solution by the blower. The first path the outside air passes through humidifier in order to control humidity for the air inside before injection thought the solution. The second path, the outside air passes over an electric heater in order to increase the air temperature before injection through the solution. Connections are used to connect the blower, heater, air-washer and the solution tank. Flexible joints between ducts are used to damp the noise and vibrations

All ducts used for the three paths has $0.05 \mathrm{~m}$ diameter. The air is injected through a series of pipes (ten pipes) and distributed in the solution with homogonous distribution. The pipes is placed which allow to the air exit at the $1 \mathrm{~cm}$ from the tank. The air velocity is controlled by the valves. Electrical heater with a thermostat up to $90^{\circ} \mathrm{C}$ and power of $1.5 \mathrm{~kW}$ is used in activation regeneration of the liquid desiccant. The liquid desiccant used in this work has an initial concentration of $40 \%$ at Copper-constantan thermocouples are fixed at different points to measure the air temperature at inlet to the solution, air exit temperature from the solution and solution. Humidity ratio of the air at inlet and exit of liquid solution tank is evaluated by measuring of air dry bulb temperature and wet bulb temperature. The solution concentration in the tank is determined by measuring the solution density and temperature. The measured density at given temperature is used to obtain the solution concentration [17]. A temperature control (up to $90^{\circ} \mathrm{C}$ ) is used for changing the temperature of the incoming air flowing through the solution tank. The aim of changing the temperature is to investigate the effect of the different air temperatures on dehumidification process.

In absorption, the moist air flows through the Calcium chloride solution. This will decrease the concentration of the solution on the tank after a certain time. In the regeneration, process the air exits from the air heater at a high temperature then flows through the solution in order to regenerate the moisture from the solution.

The data collections are carried out during 60 minutes with interval of 10 minute at different inlet conditions. After every period the wet-bulb and dry-bulb temperatures of the inlet and outlet, air measured to obtain the air humidity ratio. In addition, the solution concentration is also evaluated.

\section{PERFORMANCE ANALYSIS}

The moisture removal rate is an important parameter for measuring the thermal performance of the dehumidifier in terms of handling the latent heat load of process air:

$$
m_{d}=m_{a}\left(w_{i n}-w_{e x}\right)
$$

Where $\mathrm{m}_{\mathrm{a}}$ is the air mass flow rate at the solution inlet, $w_{\text {in }}$ is the inlet humidity in the dehumidifier inlet, $w_{o x}$ is the air humidity at dehumidifier outlet section. These parameters measured in the experimental work

The regeneration mass flow rate $m_{e v}(\mathrm{~g} / \mathrm{s})$ is calculated from the following relation:

$$
m_{e v}=m_{a}\left(w_{o x}-w_{i n}\right)
$$

The performance of dehumidifier and regenerator of a liquid desiccant system is defined in terms of non dimensional parameters related dehumidification effectiveness, cooling effect and mass transfer rate. 
Dehumidification effectiveness $\mathcal{E}_{d e}$ (also called humidity or moisture effectiveness to include both dehumidifier and regenerator) is defined as the ratio of actual change in humidity ratio of the air across the dehumidifier/regenerator to the maximum possible change in humidity ratio of air. For an insulated absorber/regenerator, the maximum possible difference in humidity ratio of air is obtained when air is in equilibrium with the inlet desiccant solution, i.e. when the partial pressure of water in the air is equal to the vapor pressure of the inlet desiccant solution and the driving force for mass transfer is zero

The dehumidification calculated from the following relation [18]

$$
\varepsilon_{d e}=\frac{w_{i n}-w_{e x}}{w_{i n}-w_{e q}}
$$

Where $w_{e q}$ is the humidity ratio of the air which air is equilibrium with the desiccant solution and calculated from the following relation?

$$
w_{e q}=0.622 \frac{p_{v}}{p_{a}-p_{v}}
$$

The cooling effect on the air is also involved in the dehumidification process if the inlet temperature is higher than that of the desiccant solution temperature. The cooling effect can be calculated from the following equation [19]

$$
\eta=\frac{T_{a, i n}-T_{a o u t}}{T_{a, i n}-T_{s}}
$$

Where

$T_{s}$ is the solution temperature

The mass transfer rate $\beta$ is obtained from the following relations (Kabeel 2004)

$$
\beta=\frac{m_{d}}{A_{r} \Delta P \Delta \tau}
$$

Where $\Delta \mathrm{p}$ is the vapor pressure difference between ambient air and desiccant surface, which can be expressed as

$$
\Delta \mathrm{p}=\mathrm{P}_{\mathrm{a}}-\mathrm{P}_{\mathrm{v}}
$$

Vapor pressure of calcium chloride solution on the bed Surface, $\mathrm{p}_{\mathrm{v}}$, can be calculated as a function of solution temperature within a temperature range from 10 to $65^{\circ} \mathrm{C}$ and concentration range from $20 \%$ to $50 \%$ according to the following equations [20]

$$
\operatorname{Ln}\left(P_{V}\right)=A(x)-\frac{B(x)}{T_{S}+111.96}
$$

Where $\mathrm{P}_{\mathrm{v}}$ is in $\mathrm{mm} \mathrm{Hg}, \mathrm{T}_{\mathrm{s}}$ in ${ }^{\circ} \mathrm{C}, \mathrm{A}(\mathrm{x})$, and $\mathrm{B}(\mathrm{x})$ are regression dependent parameters that can be expressed as a linear function of concentration according to the following relations:

$$
\begin{aligned}
& A(x)=a_{0}+a_{1} x \\
& B(x)=b_{0}+b_{1} x
\end{aligned}
$$

Where:

$$
\begin{aligned}
& a_{o}=10.0624 a_{1}=4.4674 \\
& b_{o}=739.828 b_{1}=450.96
\end{aligned}
$$

\section{ECONOMIC ANALYSIS}

There are several methods recounting the economic analysis for evaluating any investment. In the present study the present worth value and the payback period are used to assess the presented dehumidification systems. A latent load of $1.56 \mathrm{~kW}$ is used for calculations. The life cycle $(\mathrm{N})$ of the proposed system is assumed to be 10 years. The present worth factor (PWF) can be calculated as follows:

$$
P W F=\frac{1}{d-i}\left(1-\left(\frac{1+i}{1+d}\right)^{N}\right)
$$

if $i \neq d$

where $\mathrm{i}$ is the energy interest rate and $\mathrm{d}$ is the market discount rate. The life cycle savings (LCS) may be calculated as follows:

$$
\mathrm{LCS}=\mathrm{PWF} \times \mathrm{C}_{\mathrm{RC}}-\mathrm{C}_{\mathrm{IC}}
$$

where: CIC is the initial expenditure (LE) and CRC is the annual running cost.

A simple method for getting a quick evaluation of the alternatives is to calculate how long it takes to recover the initial investment, i.e. the payback period (PP):

$$
\mathrm{PP}=\ln \left(\frac{\mathrm{C}_{\mathrm{IC}} \times \mathrm{i}}{\mathrm{C}_{\mathrm{RC}}}+1\right) / \ln (\mathrm{i}+1)
$$

\subsection{Experimental Uncertainty Analysis}

Uncertainty associated with the experimental measurements is shown in Table 1. The error is calculated for thermocouples, 
slight glass. The minimum error occurred in any instrument is equal to the ratio between its least count and minimum value of the output measured

\section{EXPERIMENTAL RESULTS \& DISCUSSIONS}

Experimental tests are carried out at different inlet conditioning to study the dehumidification and humidification process with air injection thought the desiccant liquid. The input variables used in the experiment (dehumidification and humidification processes) were independent measurable parameters namely; air mass flow rate, solution concentration solution level, air temperatures and inlet humidity. The results are output dependent parameters measured or calculated from experimental data.

\subsection{Effect Of Air Flow Injection Through The}

\section{Solution On The Temperature Rise At Different}

\section{Solution Levels}

The variation of the average air temperature rise (inlet and exit air temperature difference)) at different mass flow rates and different solution levels in dehumidification process are shown in Fig. 4. The temperature difference between inlet and exit air is namely dependent on the amount of air injected through the desiccant solution. The difference reached 3-5 oC at air flow rate $0.012 \mathrm{~kg} / \mathrm{s}$ and $7.5-11 \mathrm{oC}$ at air flow rate $0.022 \mathrm{~kg} / \mathrm{s}$. The Difference value also depends on the desiccant solution level in the tank.

Table 1: Experimental uncertainty errors

\begin{tabular}{|l|l|l|l|}
\hline Instrument & Accuracy & Range & $\%$ Error \\
\hline Thermocouples & $+0.10 \mathrm{C}$ & $0-1000 \mathrm{C}$ & 0.25 \\
\hline Graduated flash & $+5 \mathrm{ml}$ & $0-1000 \mathrm{ml}$ & 1 \\
\hline Anemometer & $+0.1 \mathrm{~m} / \mathrm{s}$ & $0-15 \mathrm{~m} / \mathrm{s}$ & 0.2 \\
\hline
\end{tabular}

\subsection{The Variation Of Humidity Ratio At Different Air}

\section{Flow Rate Injection}

The temperature rise during the dehumidification process with different air injection flow rate at different solution levels $(8,10$ and $12 \mathrm{~cm}$ ). Is shown in Fig 4 . It can be seen that the temperature rise increase with the rate the injection air flow rate and solution levels. The temperature rise reached $10 \mathrm{C}$ at injection air flow rate value at air flow rate $0.022 \mathrm{~kg} / \mathrm{s}$.

The variation in the humidity ratio during the dehumidification process with different air injection shown in $\mathrm{F}$ ig 5 . The moisture removal rate increases with increasing air flow rate through the solution which being proportional to it. Higher air flow rate increases the mass transfer coefficient between the desiccant solution and air stream incoming moisture rate into the dehumidification pad, due to reduction of the contact time. It reached $11 \mathrm{~g} / \mathrm{kg}$ at $8 \mathrm{~cm}$ solution level and $13 \mathrm{~g} / \mathrm{kg}$ at $12 \mathrm{~cm}$ solution level. The value at air mass flow rate $0.012 \mathrm{~kg} / \mathrm{s}$ reached $7 \mathrm{~g} / \mathrm{kg}$ at $8 \mathrm{~cm}$ solution level and $10 \mathrm{~g} / \mathrm{kg}$ at $12 \mathrm{~cm}$ solution level.

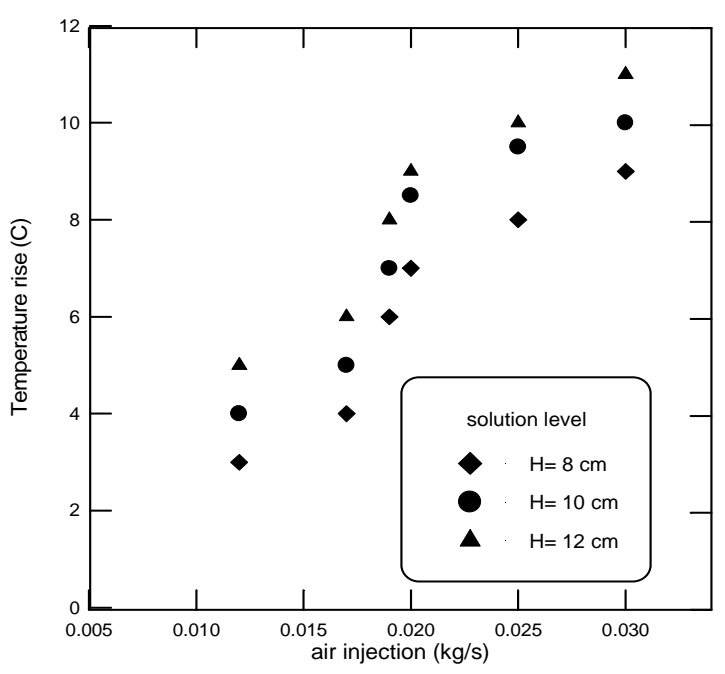

Fig. 4: Variation of air injection temperatures at different solution levels

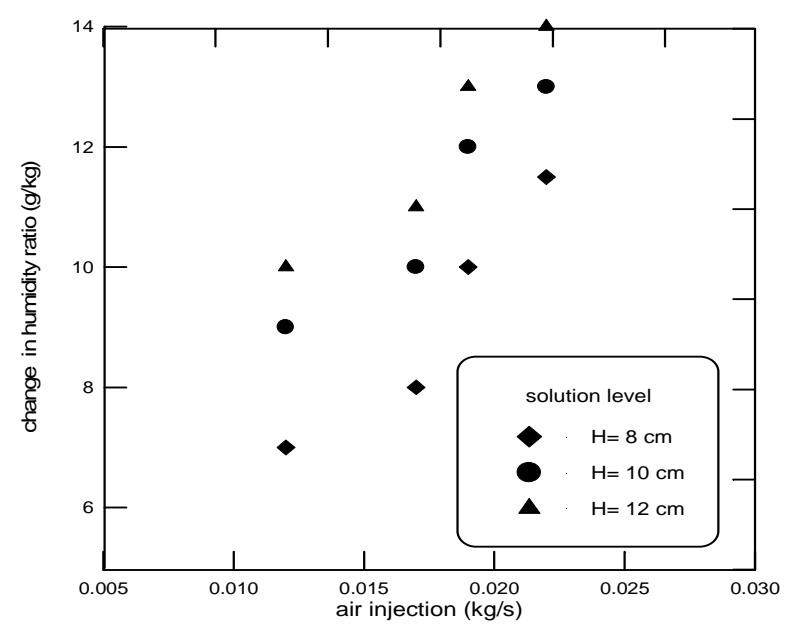

Fig. 5: Variation in the humidity ratio during the dehumidification process

\subsection{Effect Of Injection Air Temperature On The}

\section{Humidity Ratio}

Fig. 6 illustrates the variation of the average variation of the humidity ratio in the humidification process for the different inlet air temperatures 50,60, 65, 70 C and for different solution 
levels. It can be observed that the change of air humidity ratio increases with the increasing air temperature. This can be explained as the increasing of the temperature enhances the mass transfer coefficient value. The difference at regeneration temperature equals 50 reached $7 \mathrm{~g} / \mathrm{kg}$ at $8 \mathrm{~cm}$ solution level and $11 \mathrm{~g} / \mathrm{kg}$ at $12 \mathrm{~cm}$ solution level and at $70 \mathrm{C}$ the value reached $12 \mathrm{~g} / \mathrm{kg}$ at $8 \mathrm{~cm}$ solution level and 12.5 at $12 \mathrm{~cm}$ solution level $\mathrm{g} / \mathrm{kg}$. It can be observed that the humidity ratio increases with the increase of the solution level. This is due to the increases of the contact period between air and solution. Also, it is expected that the average solution concentration during the absorption period depends on the mass of solution in the tank; therefore the average potential for mass transfer is expected to be higher for higher level. Fig. 6 illustrates the variation of the average variation of the humidity ratio in the humidification process for the different inlet air temperatures 50, 60, 65, $70 \mathrm{C}$ and for different solution levels. It can be observed that the change of air humidity ratio increases with the increasing air temperature. This can be explained as the increasing of the temperature enhances the mass transfer coefficient value. The difference at regeneration temperature equals 50 reached $7 \mathrm{~g} / \mathrm{kg}$ at $8 \mathrm{~cm}$ solution level and $11 \mathrm{~g} / \mathrm{kg}$ at $12 \mathrm{~cm}$ solution level and at $70 \mathrm{C}$ the value reached $12 \mathrm{~g} / \mathrm{kg}$ at $8 \mathrm{~cm}$ solution level and 12.5 at 12 $\mathrm{cm}$ solution level $\mathrm{g} / \mathrm{kg}$. It can be observed that the humidity ratio increases with the increase of the solution level. This is due to the increases of the contact period between air and solution. Also, it is expected that the average solution concentration during the absorption period depends on the mass of solution in the tank; therefore the average potential for mass transfer is expected to be higher for higher level.

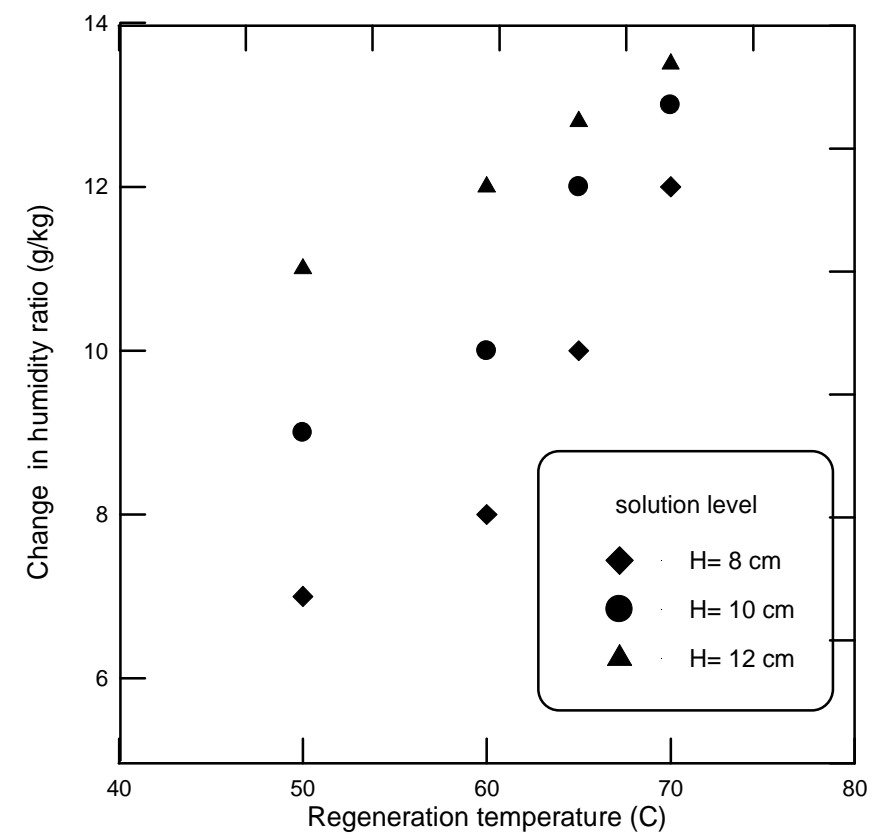

Fig. 6: variation of air exit humidity in the dehumidification process at different solution level

\subsection{Dehumidification \& Humidification Effectiveness}

The variation of the humidification effectiveness with regeneration temperature is shown in Fig. 7a, Fig. 7b. The figure shows that the humidification effectiveness reached to about 0.7. This value is higher compared with the value of reference [21]. Also it can be observed for dehumidification process that the value decreases with time. This is due the changes of the solution concentration. The decrease is higher after one hour for the higher value of the flow rate.

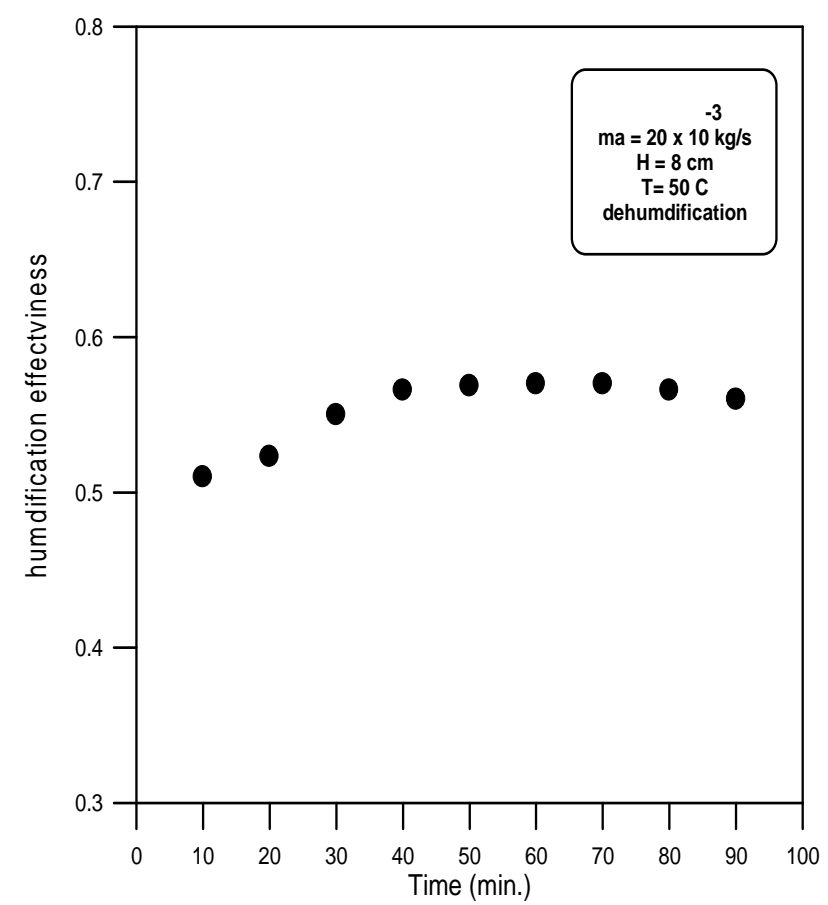

Fig. 7a: Variation of the humidification effectiveness with time 


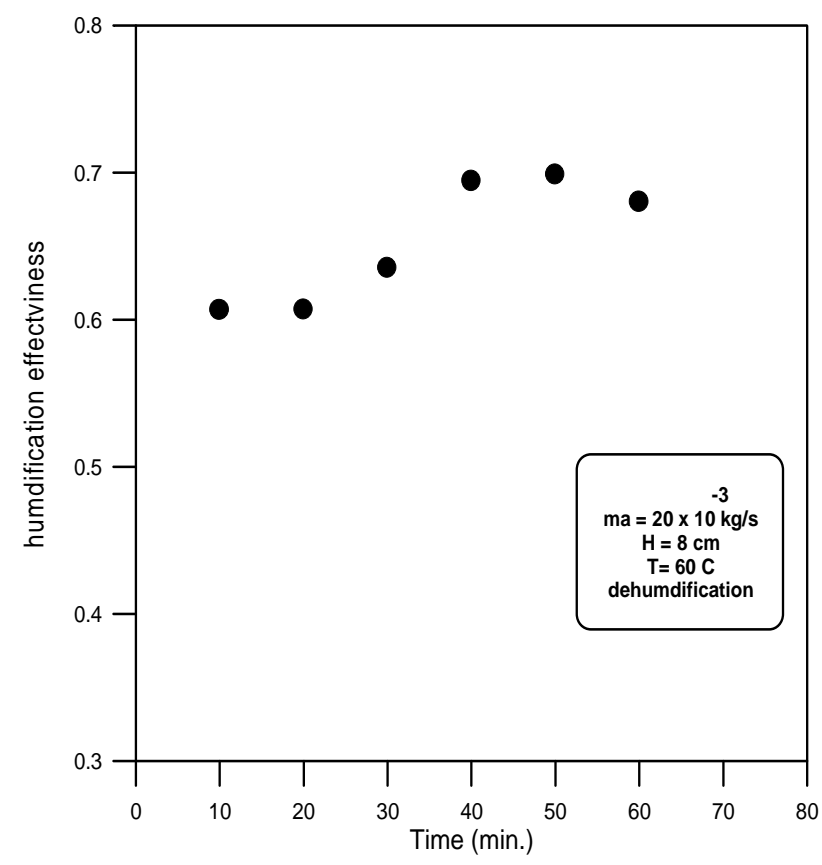

Fig. 7b: Variation of the humidification effectiveness with time

\subsection{Variation Of Cooling Effect For Dehumidification \\ Process}

Fig. 8 shows the variation of cooling effect with time which is calculated from equation 4 . It can be observed that the value depends on the flow rate and the value decreases with time till reaching minimum value.

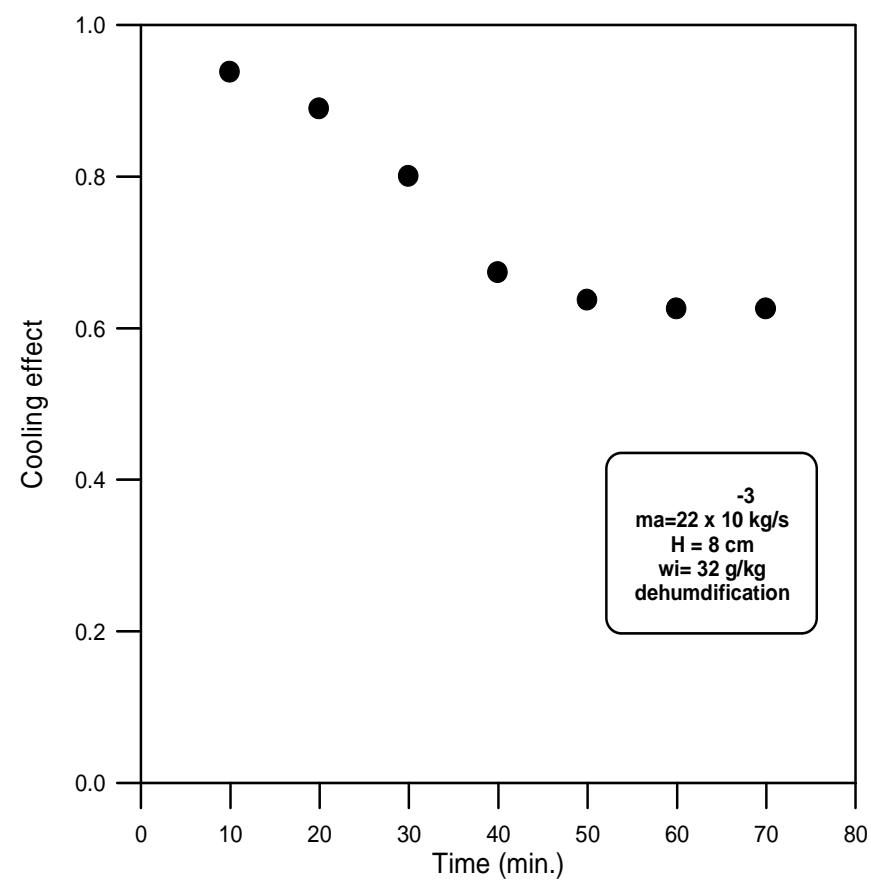

Fig. 8 Variation of the cooling effect with the time

\subsection{Variation Of Convective Mass Transfer Coefficient}

The mass transfer rate is calculated from Equation. 6 and is represented in Fig. 9 for an experimental test at the different injection air flow rate $(0.012,0.017,0.019$ and $0.022 \mathrm{~kg} / \mathrm{s})$ and at different solution levels ( 810 and $12 \mathrm{~cm}$ ). It can be observed that the convective mass transfer coefficient depends on the injection air mass flow rate and also the solution level. The value at mass air flow rate equals $0.012 \mathrm{~kg} / \mathrm{s}$ reached to $16 \mathrm{~kg} / \mathrm{s}$ $\mathrm{m} 2 \mathrm{~mm} . \mathrm{hg}$ reached to $19 \mathrm{~kg} / \mathrm{s} \mathrm{m} 2 \mathrm{~mm}$. hg Also, the Figure shows that the effect of solution level is small value at higher value of air mass flow rate 


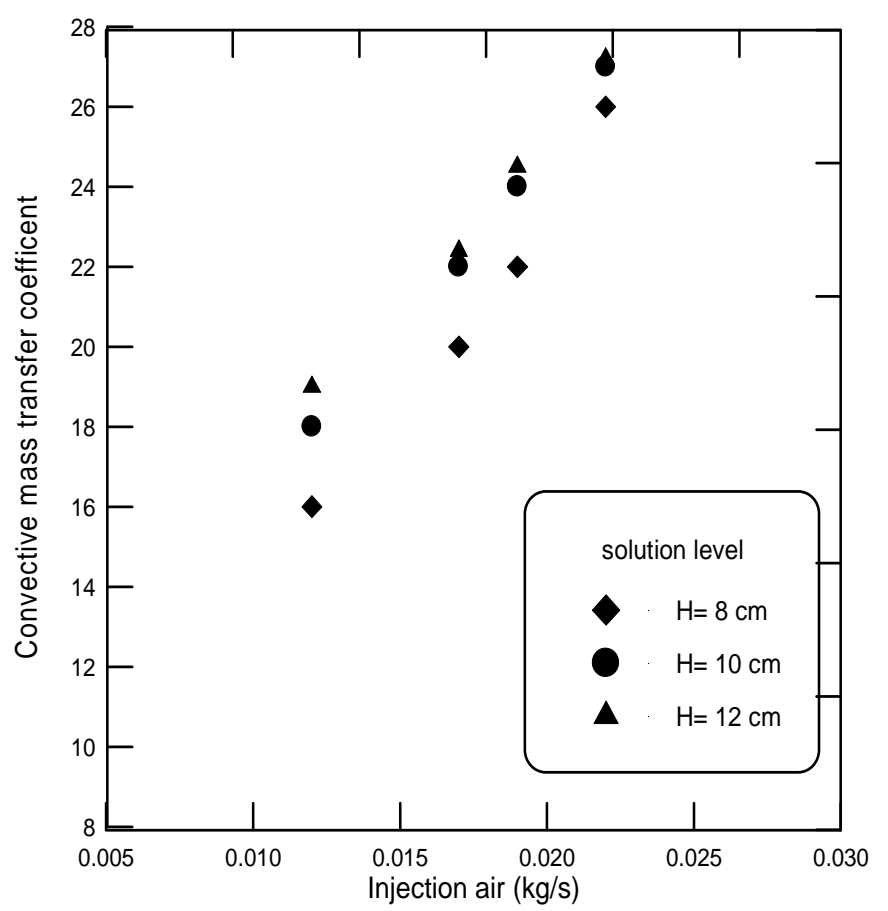

Fig. 9 Variation of the mass transfer coefficient in dehumidification process with time

\section{ECONOMIC RESULTS}

The total capital and running cost of the presented system are estimated to be 2800 L.E and 730 L.E respectively. The price of one $\mathrm{kWh}$ is assumed to be $0.4 \mathrm{LE}$ in average. The capital cost of the presented system is financed over 10 years at market discount rate $\mathrm{d}=9 \%$ and the annual cost payments are expected to inflate at a rate of $\mathrm{i}=8 \%$. The payback time is found to be 3.5 year. This system achieves a total LCS of about 3040 LE at its life cycle end.

\section{CONCLUSIONS}

This work presents an experimental research on the dehumidification of air and solution regeneration process with the air injection through the liquid desiccant $\mathrm{H} 2 \mathrm{O} / \mathrm{CaCl} 2$. The air is injected through the desiccant liquid at different air flow rates and different regeneration temperature for different solution height. The effect of individual parameters on the system performance is analyzed. The evaporation rate of water from the desiccant increases with the increase of air flow rate and solution height. The system effectiveness reached 0.75 in the dehumidification process and 0.7 in the humidification process. Mass transfer coefficient reached to $28 \mathrm{~kg} / \mathrm{s} \mathrm{m} 2 \mathrm{~mm}$. hg at flow rate equals $0.022 \times 10-3 \mathrm{~kg} / \mathrm{s}$ in the dehumidification process.

\section{REFERENCES}

[1] Ali A, Vafai K, Khaled ARA. 2003, Comparative study between parallel and counter flow Energy research ;27:725-45.

[2] Dai YJ, Zhang HF. 2004, Numerical simulation and theoretical analysis of heat and mass transfer in a cross flow liquid desiccant air dehumidifier packed with honeycomb paper. Energy Convers Manage;45:1343-56.

[3] Gommed K, Grossman G. 2006, Experimental investigation of a liquid desiccant system for solar cooling and dehumidification. Solar Energy;81:131-8.

[4 ]Ali A, Vafai K, Khaled ARA. 2004, Analysis of heat and mass transfer between air and falling film in a cross flow configuration. Int J Heat Mass Transfer;47:743-55.

[5] A.A.M. Hassan, M. Salah Hassan. 2008, Dehumidification of air with a newly suggested liquid desiccant, Renewable Energy 33 1989-1997

[6] V. C. Mei and F. C. Chen. 1992, An assessment of desiccant cooling, Oak Ridge and national dehumidification Technology, Oak Ridge national laboratory, U. S. Department of energy,

[7] A. E. Kabeel, 2010, Dehumidification and humidification process of desiccant solution by air injection. Energy 355192 - 5201

[8] Li Zhang, Chaobin Dang, Eiji Hihara.2010, performance analysis of a no-frost hybrid air conditioning system with integrated liquid desiccant dehumidification International Journal of Refrigeration 33 116-124.

[9] Sanjeev Jain, P.K. Bansal. 2007, Performance analysis of liquid desiccant dehumidification systems, International Journal of Refrigeration $30 \mathrm{pp} .861-872$.

[10] B. Shaji Mohan, M. Prakash Maiya, Shaligram Tiwari. 2008,Performance characterisation of liquid desiccant columns for a hybrid air-conditioner. Applied Thermal Engineering 28 pp. $1342-1355$.

[11] D. Pietruschka, U. Eicker, M. Huber, J. Schumacher.2006, Experimental performance analysis and modelling of liquid desiccant cooling systems for air conditioning in residential buildings, International Journal of Refrigeration 29 pp.110-124.

[12] C. S. Khalid Ahmed, P. Gandhidasan and A. A. AlFarayedhi. 1997, Simulation of a hybrid liquid desiccant based air-conditioning system. Applied Thermal Engineering Vol. 17, No. 2, pp. 125-1 34,

[13] A.I. Lowenstein, M.H. Dean. 1992, The effect of regenerator performance on a liquid desiccant airconditioner, ASHRAE Transactions: Symposia 98 (1) pp. 704-711.

[14] C.S.P. Peng, J.R. Howell. 1984, The performance of various types of regenerators for liquid desiccants, Journal of Solar Energy Engineering, Transactions of the ASME 106 pp. 133-141. 
[15] Rahamah A, Elasayed MM, Al-Najem NM. 1998,A numerical solution for cooling and dehumidification of air by a falling desiccant film in parallel flow. Renew Energy13(3): pp.305-22.

[16] Rahamah A, Elsayed MM, Al-Najem NM.2006, Numerical investigation for the heat and mass transfer between parallel flow of air and desiccant falling film in a fin-tube arrangement. HVAC R Res 6(4):pp.307-23.

[17] Yango Y, Zheng X, Chen Z. 2007, Experimental study on dehumidifier and regeneration of liquid desiccant cooling air conditioning system. Build Environ;42(7):pp. 2505-11.

[18] Ali A, Vafai K. 2004, An investigation of heat and mass transfer between air and desiccant film in an inclined parallel and counter flow channel. Int $\mathbf{J}$ Heat Mass Transfer 47: pp.1745-60.

[19] Kabeel A. E.2004, Augmentation of the performance of solar regenerator of open absorption cooling system, renewable energy 30 pp. 327-338

[20] V. Oberg, D.Y. Goswami, 1998, Experimental study of the heat and mass transfer in a packed bed liquid desiccant air dehumidifier, Journal of Solar Energy Engineering, Transactions of the ASME 120 pp. 289297.

[21] A.I. Lowenstein, R.S. Gabruk, 1992, The effect of absorber design on the performance of a liquid desiccant airconditioner, SHRAE Transactions: Symposia $98 \mathrm{pp}$. $712-720$.

\section{NOMENCLATURE}

A (x) and B (x) Regeneration dependent parameters

$\mathrm{a}_{\mathrm{o}}, \mathrm{a}_{1}, \mathrm{~b}_{\mathrm{o}}, \mathrm{b}_{1}$ Constants, (-)

$m_{d} \quad$ The rate of water absorption, $(\mathrm{g} / \mathrm{s})$

ma The air mass flow rate at the solution inlet, $(\mathrm{g} / \mathrm{s})$

$m_{e v} \quad$ The regeneration mass flow rate, $(\mathrm{g} / \mathrm{s})$

$m_{e v} \quad$ The rate of water evaporated, , $(\mathrm{g} / \mathrm{s})$

$m_{a}$ The air flow rate, , $(\mathrm{g} / \mathrm{s})$

$\mathrm{H} \quad$ solution level, $\mathrm{cm}$

$w_{\text {in }} \quad$ The inlet humidity in the dehumidifier inlet, $\mathrm{g} / \mathrm{kg}$

$w_{o x}$ The air humidity at dehumidifier outlet section, $\mathrm{g} / \mathrm{kg}$

$w_{e q} \quad$ The humidity ratio of the air which air is equilibrium with the desiccant solution, $\mathrm{g} / \mathrm{kg}$

$p_{v} \quad$ The vapor pressure of calcium chloride solution on the bed Surface, $\mathrm{mm} \mathrm{Hg}$

$p_{a} \quad$ The pressure of ambient air, $\mathrm{mm} \mathrm{Hg}$

$\mathrm{x} \quad$ The solution concentration
$\mathrm{T}_{\mathrm{s}} \quad$ The solution temperature, $\mathrm{C}$

$\mathcal{E}_{d e} \quad$ The dehumidification effectiveness

$\beta \quad$ The mass transfer rate, $\mathrm{kg} / \mathrm{s} \mathrm{m}^{2} \mathrm{~mm}$. hg

$\Delta \mathrm{p} \quad$ The vapor pressure difference between ambient air and desiccant surface, $\mathrm{mm} \mathrm{Hg}$

$\eta \quad$ The cooling effect on the air, (-) 